\title{
SUCCESSFUL PREGNANCY IN A DWARF : A RARE CASE REPORT
}

\author{
NAHID YUSUF ${ }^{1}$, HASINA AKTER $^{2}$, MD AHMED ALI ${ }^{3}$, LATIFUR RAHMAN $^{4}$
}

\begin{abstract}
:
Miraculous birth: Standing at just 3'5"(104.14cm) tall, 28 years old proportionate dwarf lady weighing $20 \mathrm{~kg}$ was succeeded in giving birth to a girl at $36^{+}$weeks of pregnancy by cesarean section in June, 2013 making her the smallest woman ever reported to give birth to apparently healthy looking, and average-sized female baby in Bangladesh. Detailed clinical examination of the neonate performed by the neonatologist revealed no obvious external congenital anomalies and infantogram after 6 weeks also revealed normal study.
\end{abstract}

Key words: Dwarfism, Achondroplasia, Midget, Little people

\section{Introduction:}

Dwarfism occurs when an individual person or animal is short in stature (less than $147 \mathrm{~cm}$ or 4 feet 10 inches) resulting from a medical condition resulting in abnormal (slow or delayed) growth ${ }^{1}$.

It is rare for a dwarf to conceive and when they do the pregnancy does not last long because of the uterus size. Women with disproportionate dwarfism may develop respiratory problems during pregnancy. A cesarean delivery is almost always necessary because the size and shape of the pelvis doesn't allow for successful vaginal delivery. ${ }^{2}$

Here we reported an interesting case of pregnancy in the shortest dwarf in Bangladesh (so far reported) with successful feto-maternal outcome.

1. Dr. Nahid Yusuf, Assistant Professor, Dept. of Obs \& Gynae, Rajshahi Medical College

2. Dr. Hasina Akter, Professor and Head, Dept. of Obs \& Gynae, Rajshahi Medical College

3. Dr. Md Ahmed Ali, Associate Professor, Dept. of Neurology, Rajshahi Medical College

4. Dr. Latifur Rahman, Professor and Head, Dept. of Anaesthesiology, Shahid Ziaur Rahman Medical College

Correspondence: Dr. Nahid Yusuf, Assistant Professor, Dept. of Obs \& Gynae, Rajshahi Medical College, E-mail: nahid.yusuf@ yahoo.com

\section{Case Report:}

Mrs. Masuma, a dwarf lady of 28 years, 2nd gravida, para-0+1(MR), Muslim, housewife of lower class family was attended in Gynae outpatient department (OPD) of Rajshahi Medical College Hospital (RMCH) with complains of 2 months amenorrhea and symptoms of early pregnancy. She had regular menstrual cycle with average flow and duration but had delayed menarche at 18 years.

According to her statement, she has 3 brothers and 3 sisters. All but one of her family members are in average height and body built, one of her sister (Pic 3 ) has height of 4'5" $(134.6 \mathrm{~cm})$. Her husband was an orphan and lived a destitute life. On 2002, a neighbor introduced him with dwarf Masuma. He fall in love and in 2003, the 24 years old, 5'6" tall man got married to18 years old, $104.14 \mathrm{~cm}$ tall Masuma (Pic 1). Since then he is enjoying his conjugal life as house husband.

"In theory, it is recommended that dwarf women would not get pregnant and would not try to give birth to child, because of their lives risk and even worse, the possibility of dwarfism in the offspring is also high," keeping it in mind, this couple terminated their $1^{\text {st }}$ pregnancy by MR. After adequate counseling, the couple decided to continue the present pregnancy and further evaluated.

She had no history suggestive of bronchial asthma, heart disease, chronic renal disease, malabsorption syndrome, DM or thyroid disorder.

On clinical examination, she was a proportionate dwarf (body parts being proportional but smaller), having a height of $104.14 \mathrm{~cm}$, severely malnourished, weight only $10 \mathrm{~kg}$, and BMI-18.44Kg/M² and MUAC- $15 \mathrm{~cm}$. Her Voice was childish but had normal intelligence. 
She had no abnormal bone alignment, no early degenerative joint disease, no lordosis or scoliosis. She was mildly anaemic, thyroid gland was not enlarged, and breasts were well developed and showed normal pregnancy changes. Musculoskeletal system revealed low muscle bulk and bony mass, but muscle power was normal. Cardio-respiratory and other systems were normal. Abdominal examination showed nothing abnormality and local examination revealed normal external genitalia.

Routine antenatal and specific investigations including ECG \& ECHO were found normal except $\mathrm{Hb} \%$ which was $9 \mathrm{gm} / \mathrm{dl}$. USG showed single live pregnancy of 08 weeks and other abdominal organs were normal.

To find out the possible causes of dwarfism, thyroid function test and growth hormone assay were done and the results were within normal range. She was followed up carefully with regular antenatal checkup with special advice for high calorie \& protein rich diet. Anaemia treated with oral iron and Folic acid. She

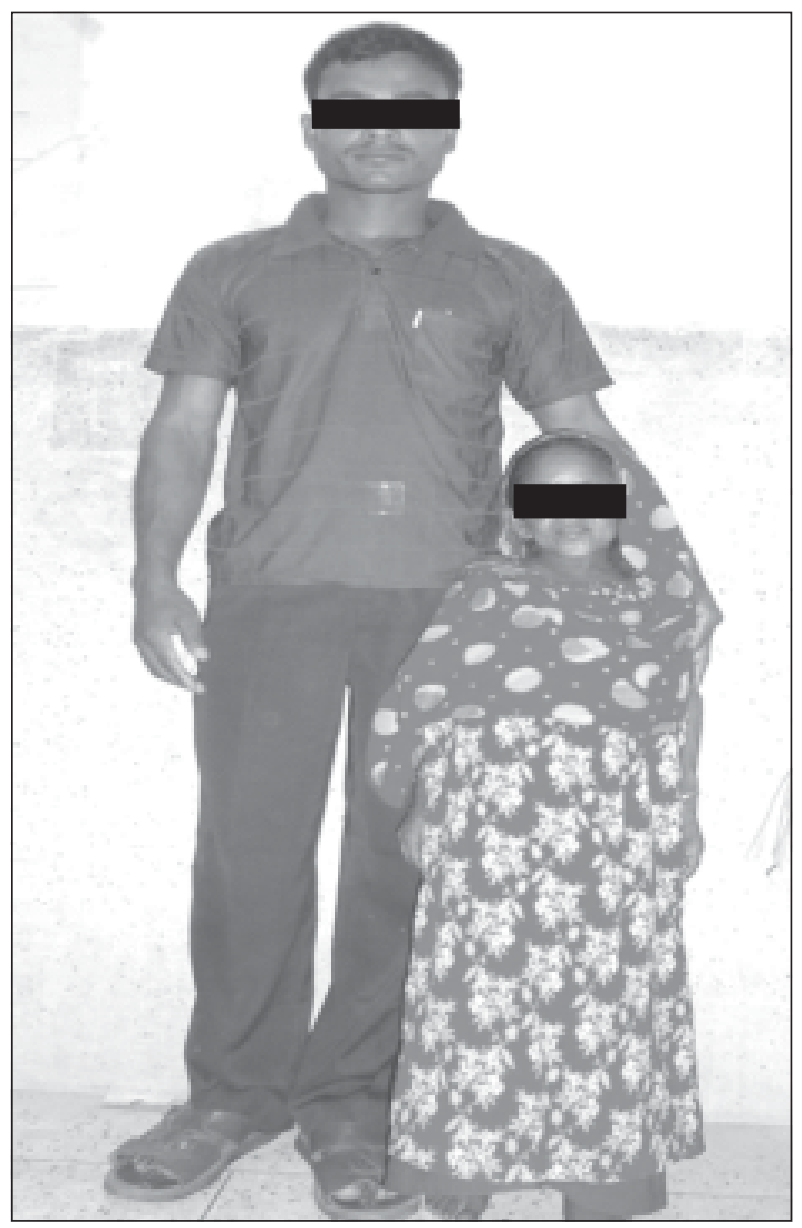

Fig.-1

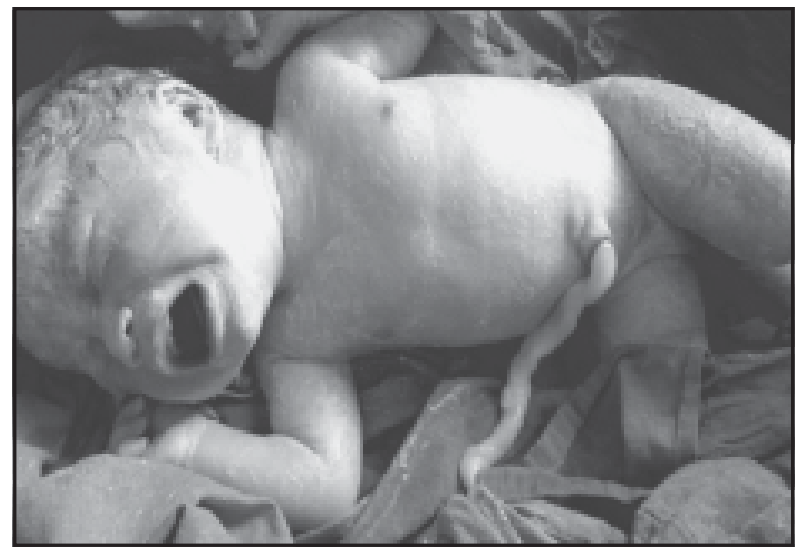

Fig.-2

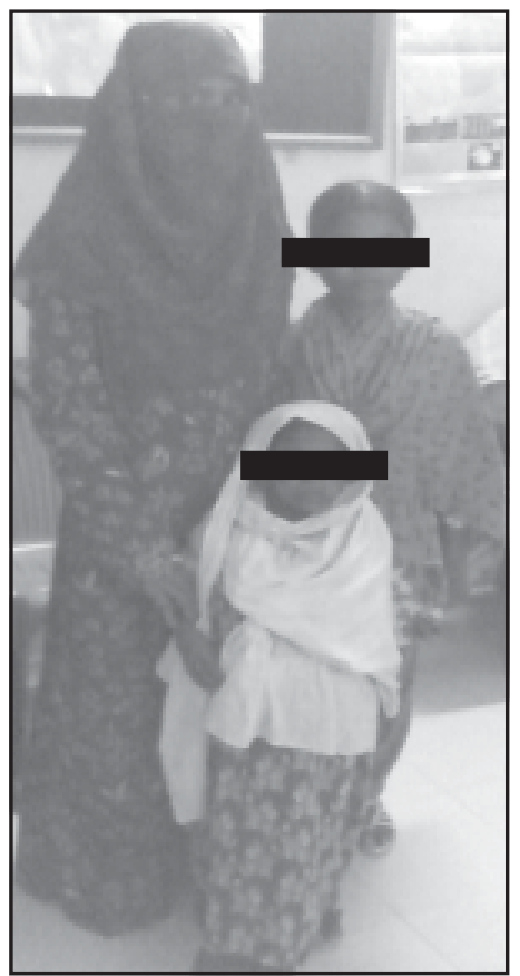

Fig.-3

was immunized with 2 doses of Tetanus toxoid. Till 30 weeks of gestation her pregnancy was uneventful.

The next months proved to be hard time for the dwarf mother since the baby grew bigger and the symptoms of the mother became heavy. At 34 weeks pregnancy, she was admitted in $\mathrm{RMCH}$ due to physical discomfort in her daily activities. On admission, she was normotensive and non-diabetic, her body weight was only $20 \mathrm{Kg}$.

In hospital she was on close supervision and improved diet. Elective caesarean section was done on 02-062013 at $36^{+}$weeks pregnancy under spinal 
anaesthesia by a senior and expert anaesthetist and a female baby weighing $2.5 \mathrm{~kg}$ was delivered (Pic 2).

"Congratulations! Your wife gave birth to a daughter". Her husband having waited outside the OT for over an hour, finally got the news from nurse that his dwarf wife and his child were both safe.

"I am so excited to have a baby", the fresh father said in tears recalling the difficulties he and his dwarf wife had experienced during the last 9 months.

Intra operative findings in our case: The size of uterus and LUS was well developed. Following delivery placenta was also was found average sized. There was no problem intra-operatively. Postoperative period was also uneventful. Newborn was completely okay externally, examined by pediatrician in $\mathrm{OT}$, before discharge and 6 weeks after delivery.

\section{Discussion:}

Dwarfism can be caused by about 200 distinct medical conditions, such that the symptoms and characteristics of individuals with dwarfism vary greatly. ${ }^{3}$

Disproportionate dwarfism is characterized by one or more body parts being relatively large or small in comparison to those of an average-sized adult. Achondroplasia is the commonest cause of shortlimbed dwarfism and characterized by proportionately shorter limbs than the trunk, increased spinal curvature, and distortion of skull growth with characteristic facial features. It is a rare genetic disorder inherited as autosomal dominant trait but most cases $(80 \%)$ are due to mutations in the fibroblast growth factor receptor-3gene located on $4 \mathrm{p}$. The majority of cases is sporadic and results from a de novo paternal mutation. This defect exclusively inherited from the father and becomes increasingly probable with paternal age; specifically males reproducing after thirty five $\mathrm{e}^{4,5}$.

In case of proportionate dwarfism, extreme shortness with proportional body parts usually has a hormonal cause, such as growth-hormone deficiency (also known as pituitary dwarfism), defect in receptor for growth hormone and Hypothyroidism. Growth hormone deficiency has no single definite cause. It can be caused by mutations of specific genes, damage to the pituitary gland, Turner's syndrome, poor nutrition ${ }^{3}$, or even stress (leading to psychogenic dwarfism). Serious chronic illnesses may also produce dwarfism as a side effect. In societies where poor nutrition is widespread, the average height of the population may be reduced below its genetic potential by the lack of proper nutrition.

In cases of proportionate dwarfism the sexual development is often delayed or impaired into adulthood. Hypotonia, or low muscle tone, is common in dwarfs, but intelligence and lifespan are usually normal. It is rare for achondroplasia sufferers to conceive and when they do the pregnancy does not last long because of the uterus size $\mathrm{e}^{6-7}$.

Defining dwarfism by height alone is problematic because short stature in itself is not a disorder and it can be inherited without any coexisting disease. Short stature in the absence of a medical condition is not generally considered dwarfism for example; pygmies have adult male heights of less than $150 \mathrm{~cm}$ (4 feet 11 inches) on average $^{8}$.

For people, in addition to the medical aspect of the condition, there are social and sociological aspects as well. For a person with dwarfism, heightism can lead to ridicule in childhood and discrimination in adulthood $^{9-10}$.

There is no single treatment for dwarfism. Dwarfism resulting from malnutrition or a hormonal abnormality may be treated with an appropriate diet or hormonal therapy. Growth hormone deficiency may be remedied via injections of Human Growth Hormone ( $\mathrm{HGH}$ ) during early life before the child's' growth plates fuse. . Genetic defects of most forms of dwarfism caused by bone dysplasia cannot be corrected, so therapeutic interventions are typically aimed at preventing or reducing pain or physical disability, increasing adult height, or mitigating psychosocial stresses and enhancing social adaptation. Pain and disability may be ameliorated by physical therapy, braces or other orthotic devices, or by surgical procedures. The only simple interventions that increase perceived adult height are dress enhancements, such as shoe lifts or hairstyle ${ }^{11-12}$.

Many types of dwarfism are impossible to prevent because they are genetically caused which may be identified with genetic testing.

In our case since her parents are found to be normal stature and no other affected family member and her $\mathrm{GH}$ level is within normal range this woman can be attributed to receptor problem to $\mathrm{GH}$. 
According to medical records, there have been four such previous instances where women who delivered were $108 \mathrm{~cm}, 109 \mathrm{~cm}$ and $112 \mathrm{~cm}$ tall (Indian dwarf) and $70 \mathrm{~cm}$ tall Chinese dwarf woman who gave birth to twins ( 1 alive \& 1 dead). So far recorded our Masuma is the $1^{\text {st }}$ proportionate dwarfism who successfully able to continue pregnancy near term and gave birth to a normal healthy baby.

\section{References:}

1. "Dwarfism". From Wikipedia. Retrieved 2009-0222.

2. Tyson JE, Barnes AC, McKusick VA, Scott Cl, Jone GS. Obstetric and gynecological considerations of dwarfism. Am J Obstet and Gynecol 1970 Nov; 108(5):688-703.

3. Kozma, Chahira. "Causes of Dwarfism". American Journal of Medical Genetics 2005; 140A (4): 303311

4. Escamilla RF, Hutchings JJ, Li CH, Forsham P. "Dwarfism and Bone Dysplasias". Calif Med; 105 (2): 104-10

5. William A Horton, Judith G Hall,Jaqueline T Hech. Achondroplasia. The Lancet 2007; 370 : 95-82
6. "Dwarfism: Symptoms". MayoClinic.com. Mayo Foundation for Medical Education and Research. Retrieved 2009-01-29.

7. Ghumman S, Goel N, Rajaram S, Singh K.C, Kansal B, Dewan P. Pregnancy in an achondroplstic dwarf. Journal of the Indian Medical Association 2005; 103(10):536-538

8. Encyclopædia Britannica - Pygmy, retrieved on 2013-04-25

9. Trikha A, Goyal K, Sadera GS, Singh M. "Dwarfism: Complications". Anaesth Intensive Care 2002; 30(1): 96-8.

10. Adelson, Betty M. The Lives of Dwarfs: Their Journey From Public Curiosity Toward Social Liberation. American Journal of Medical Genetics 2003; Part A 120A (4): 447-58.

11. Escamilla RF, Hutchings JJ, Li CH, Fors "Dwarfism: Treatment and drugs". Calif Med 1966; 105 (2): 104-10.

12. Hagenäs L, Hertel T. "Skeletal dysplasia, growth hormone treatment and body proportion: comparison with other syndromic and nonsyndromic short children". Horm. Res. 2003; 60 Suppl 3: 65-70. 